\title{
The Effect of Stress on Internet Game Addiction Trends in Adults: Mindfulness and Conscientiousness as Mediators
}

\author{
Taeyeong Choi ${ }^{1}$, Jae Woo Park ${ }^{\circledR}$, and Dai-jin Kim ${ }^{2}$ \\ 'Department of General Counseling, The Korea Counseling Graduate University, Seoul, Republic of Korea \\ ${ }^{2}$ Department of Psychiatry, Seoul St. Mary's Hospital, College of Medicine, Catholic University of Korea, Seoul, Republic of Korea
}

Objective This study examined the mediating effect of mindfulness and consciousness among five factors on the effect of stress on Internet game addiction tendency.

Methods An online survey was conducted on 400 men and women between their 20 s and 40s across Korea. The scales used in the study were the Internet game addiction scale based on the DSM-5, Perceived Stress Scale, Mindfulness Scale, and Five-Factor Personality Scale. For data analysis, structural equation modeling was conducted, and Sobel verification was carried out to verify the significance of the mediating effects.

Results The results of the study are as follows: Stress showed a positive correlation with Internet game addiction tendency, mindfulness mediated the effect of stress on Internet game addiction tendency.

Conclusion Of the five personality factors, conscientiousness also mediated the effect of stress on Internet game addiction tendency. This study highlights the need for further research for individuals with game addiction tendency.

Psychiatry Investig 2021;18(8):779-788

Key Words Internet game addiction; Big-five personality traits; Conscientiousness; Stress; Mindfulness.

\section{INTRODUCTION}

Game addiction is a form of behavioral addiction that shows impulsiveness, indifference to interpersonal relationships, association with other addictions, and psychological and physical symptoms when the game is stopped. ${ }^{1}$ As most modern games are based on the Internet due to the development and dissemination of the Internet, the term "Internet gaming disorder" has been adopted to denote game addiction in a condition where DSM-5 requires further research: over the past 12 months, failure of excessive control over Internet games, obsession, ex-

Received: September 13, 2020 Revised: December 13, 2020

Accepted: June 9, 2021

$\triangle$ Correspondence: Jae Woo Park, PhD

Department of General Counseling, The Korea Counseling Graduate University, 366 Hyoryeong-ro, Seocho-gu, Seoul 06722, Republic of Korea

Tel: +82-2-584-6851, Fax: +82-2-584-6858, E-mail: thanotos@kcgu.ac.kr

$\triangle$ Correspondence: Dai-jin Kim, MD, PhD

Department of Psychiatry, Seoul St. Mary's Hospital, College of Medicine, Catholic University of Korea, 222 Banpo-daero, Seocho-gu, Seoul 06591, Republic of Korea

Tel: +82-2-2258-6086, Fax: +82-2-594-3870, E-mail: kdj922@chol.com

(c) This is an Open Access article distributed under the terms of the Creative Commons Attribution Non-Commercial License (https://creativecommons.org/licenses/bync/4.0) which permits unrestricted non-commercial use, distribution, and reproduction in any medium, provided the original work is properly cited. perience of abstinence when games are stopped, decreased interest in other hobbies or entertainment, continuous use of tolerance, awareness of psychological and social problems, false reporting of Internet game playing time to others, and the use of Internet games to escape negative mood are factors used to diagnose Internet gaming disorders.

In addition, the 72nd World Health Organization (WHO) general assembly included "gaming disorders" in the 11th International Classification of Diseases (ICD) standard. In content, gaming disorder refers to continuous or repetitive game behavior patterns both online and offline. The criteria are continuing or expanding game play, even if it causes serious damage to the individual or to family, society, education, or employment, or important behaviors such as the inability to control the game (such as frequency, intensity, and duration), to such an extent that the game is given priority over other life concerns and priorities of everyday life. If all three of the above criteria are met and continue for more than 12 months, diagnosis will be made, but severe cases may be diagnosed after a shorter duration.

Internet game addiction makes it difficult to distinguish between the real world and the virtual world, and it leads to with- 
drawal symptoms such as anxiety and illusions when the individual is not playing games, leading to serious difficulty in concentration, poor academic performance, and daily life. ${ }^{2}$

Adults' addiction to Internet games can have more serious consequences than in children and teenagers. Adults primarily use gambling or violent games; show reduced social productivity; and experience personal impacts on their homes, jobs, and studies. ${ }^{3-5}$ In adults, Internet game addiction is also a direct cause of the disintegration and collapse of the family, and is likely to lead to anti-social behavior and crime.,

Stress is defined as the physiological and psychological responses to internal and external perceptions of the body, whereby stress causes it to respond to specific needs. ${ }^{7}$ If stress is not addressed in everyday life events that threaten an individual's well-being when the resources or capabilities available to an individual have reached or exceeded his or her limits. ${ }^{8,9}$

Depression, anxiety, neurosis, pain, and physical symptoms can emerge when stress is not resolved with appropriate coping methods and when avoidant coping methods are used..$^{10}$ Avoidant coping involves avoiding stress stimuli by doing other unrelated tasks in stressful situations. ${ }^{11}$

Many people choose various leisure activities to cope with stress, ${ }^{12,13}$ including using the Internet, which is easily and quickly accessible. People are more likely to develop Internet addiction when unsatisfactory experiences persist in their daily lives and when they fail to try other coping methods. ${ }^{14}$

Games account for a large portion of Internet use. One study found that games account for $81.3 \%$ of all content used among Internet and smartphone users. A considerable number of people who are prone to Internet addiction show markedly greater use of games than other content. ${ }^{15}$ In a survey of online game users, they ranked "to relieve stress" as the most common reason for gaming ("to get rid of stress," 59.9\%). ${ }^{16}$ However, while games allow temporary relief of stress, they do not ultimately solve stress by addressing its cause. To determine how to use games as a means of relieving stress without experiencing addiction, research is needed to find the variables that mediate its use. $^{17}$

Mindfulness is the process of intentionally observing the body and mind and accepting what is being experienced at that moment; Kabat-Zinn defined it as the ability to focus attention on the moment. ${ }^{18,19}$ Teasdale et al. ${ }^{20}$ stated that " $[\mathrm{u}]$ sing cognitive therapy based on mindfulness, we can combine not to obsess with self-awareness, distance placement, and higher cognitive skills to recognize stress factors as temporary phenomena that pass by, and reduce stress through self- and threat awareness of self-awareness." It was also found that coping with stress through mindfulness meditation was effective in preventing and treating several bodily diseases caused by stress. ${ }^{21}$ Such a mindset is a strong cognitive behavioral response strategy ${ }^{22}$ in response to stress events.

Mindfulness is used not only to cope with stress but also to treat addiction. ${ }^{23}$ Mindfulness causes awareness of the triggers of addiction and reduces or prevents the desire for addiction so that other options are available. ${ }^{24}$ It can help control Internet addiction and game addiction. Mindfulness enables receptive attention to momentary phenomena, allowing for conscious self-regulation by helping increase the awareness of problematic Internet use with a critical attitude. ${ }^{25}$ In addition, it allows individuals to recognize their needs more clearly and respond to internal and external pressures more flexibly through an awareness of the state of conflict and maladjustment. Motivation for control of the game is thereby enhanced, leading to more controlled behavior. ${ }^{26}$ These earlier studies suggest that, in situations involving stress, mindfulness is a factor that can reduce stress and, thus, can reduce the level of addictions, such as game addiction.

Lazarus and Folkman ${ }^{9}$ argued that under stress, personality has an important effect on assessing and coping with it. Personality leads to the determination of how to cope with stress and affects the perception of the efficacy of the coping method. In other words, differences in responding to stress events are based on differences in response styles depending on individual character. ${ }^{27}$ In particular, among the five personality factors, conscientiousness is one that can predict stress. A study of college students conducted by Vollath and Torgersen ${ }^{28}$ found that conscientiousness was related to stress experience and coping. High conscientiousness showed the most favorable profile for dealing with stress while low conscientiousness showed vulnerability to stress and coping.

Conscientiousness can develop even after adulthood. A study of adults aged 21 to 60 years showed that conscientiousness changed significantly throughout early and mid-adult periods, and that it was also found to change, albeit modestly, in later age groups as compared to their early years. ${ }^{29}$ This personality factor, integrity, could change because the early stages of an adult career were marked by promotions and forming a committed partnership. ${ }^{30,31}$

Conscientiousness refers to personality traits of a high selfregulation, a high sense of responsibility, observing social norms or principles, and diligence and order. ${ }^{32}$ Conscientiousness also has the strongest conceptual characteristics of controlling impulsiveness by acting to resist impulses, manage desires, and actively control behavior. ${ }^{33}$ The impulse control of conscientiousness and its nature of behavioral control also allows it to control addiction behavior. In a study of teenagers and college students, subjects who showed high levels of Internet addiction showed poor conscientiousness. ${ }^{34}$ A game addiction study of middle school students showed the negative correlation of conscientiousness with the effect on game addiction. ${ }^{35}$ 
As discussed above, people who use evasive methods in stressful situations are likely to fall into Internet game addiction. In this process, it is assumed that mindfulness will lead to maintaining distance from stress situations and alleviate the craving for games by recognizing the triggers of game addiction, creating opportunities to make other choices. Personality also allows the assessment of and coping with stressful situations. In particular, conscientiousness is assumed to control current desires and impulses, thereby reducing Internet game addiction, an evasive way of coping.

The research questions are as follows: Research Question 1. Is greater stress associated with a greater likelihood of addiction to Internet games? Research Question 2. Will mindfulness mediate the effect of stress on internet game addiction tendency? Research Question 3. How is stress associated with the Five Factor in their effects on Internet game addiction?

\section{METHODS}

\section{The object of study}

Based on demographic ratios, online surveys of adults in their 20 s to 40 s across the country were conducted by research companies to collect the data. The data of 400 people who participated in the data collection were included in the final analysis, of whom 206 were men $(51.5 \%)$ and 194 were women (48.5\%). The age distribution was $28.5 \%$ were in their $20 \mathrm{~s}, 33.3 \%$ in their $30 \mathrm{~s}$, and $38.5 \%$ in their $40 \mathrm{~s}$. The demographic characteristics of the study participants are shown in Table 1.

\section{Analysis of internet game addiction ratios}

The means and standard deviations of Internet game addiction measures were checked to determine the tendency of Internet game addiction across subjects. The average and standard deviation of the scale of game addiction were 1.27 and 2.04 , respectively. Of all participants, $10.25 \%$ showed a tendency toward addiction to Internet games, as shown in Table 2. This figure is similar to that found in the Korea Creative Content Agency's ${ }^{15}$ survey of gaming and immersion, which found rates of $2.8 \%$ for over-indulgence and $10.9 \%$ for over-indulgence risk.

\section{Measurements}

\section{Internet Game Addiction Trends Scale}

The measure of Internet game addiction was developed by Petry et al..$^{36}$ based on the DSM-5. The scale has been translated into a total of 11 languages using recommendations on the process of translation and application of the World Health Organization's scale, including South Korea, and that was available for use in this study without needing translation. It in-
Table 1. The demographic characteristics of the participants

\begin{tabular}{|c|c|c|}
\hline Categories & Frequency & Ratio \\
\hline \multicolumn{3}{|l|}{ Gender } \\
\hline Men & 206 & 51.5 \\
\hline Women & 194 & 48.5 \\
\hline \multicolumn{3}{|l|}{ Current age } \\
\hline $20-29$ & 114 & 28.5 \\
\hline $30-39$ & 133 & 33.3 \\
\hline $40-49$ & 153 & 38.5 \\
\hline \multicolumn{3}{|l|}{ Educational attainment } \\
\hline High school graduate & 51 & 12.8 \\
\hline College student & 38 & 9.5 \\
\hline College graduate & 283 & 75.3 \\
\hline Post-graduate or higher & 28 & 7.0 \\
\hline \multicolumn{3}{|l|}{ Occupation } \\
\hline Officer & 253 & 63.3 \\
\hline Student & 58 & 14.5 \\
\hline Freelance & 17 & 4.3 \\
\hline Not employed & 39 & 9.8 \\
\hline Other & 33 & 8.3 \\
\hline \multicolumn{3}{|l|}{ Monthly income } \\
\hline Less than 2 million won & 163 & 40.7 \\
\hline Less than 4 million won & 157 & 39.3 \\
\hline Less than 6 million won & 68 & 17.0 \\
\hline Over 6 million won & 12 & 3.0 \\
\hline
\end{tabular}

Table 2. Results of participants' tendency to addiction to Internet games

\begin{tabular}{lcc}
\hline Classification of addiction orientations & Frequency & Ratio \\
\hline Addiction trend group & 41 & 10.25 \\
General usage group & 359 & 89.75 \\
\hline
\end{tabular}

cludes a total of nine questions, e.g., "Do you spend a lot of time thinking about the game even when you are not playing, or planning when you are not able to play next?" and "Do you feel lethargy, irritation, depression, anger, worry, sadness?", and each sentence is in the form of a yes/no question. Since this study was conducted on average adults, the term "gaming addiction tendency" was adopted in place of "game addiction." In this study, the internal convergence was found to be 0.833 .

\section{Stress Scale}

A perceived stress scale developed by Cohen et al. ${ }^{37}$ and adapted by Park and $\mathrm{Seo}^{38}$ was applied. The perceived stress scale consisted of a total of 14 questions scored on a five-point Likert scale: very often $=4$, quite often $=3$, sometimes $=2$, nearly never $=1$, and never $=0$.

The perceived stress measures in the study of the reform and 
validity of Park and $\mathrm{Seo}^{38}$ are divided into two sub-factors, "positive perception" and "negative perception." However, in a previous study ${ }^{39}$ that validated the perceived stress scale, the overall level of perceptual stress was assessed by adding the two subfactors together. The study by Park and $\mathrm{Seo}^{38}$ indicated that the two sub-factors assessed different aspects of stress as the questions on "positive perception" had less to do with "negative perception" even after being scored inversely. These perceived stress measures were also identified in other teacher studies. ${ }^{40,41}$

Of the two sub-factors, the questions of "negative perception" confirm the uncontrollable, unpredictable, and overwhelming character of such a perception and indicate that the higher this score, the more stressful it is. Preliminary studies show that the convergence of measurement models with two factors of negative and positive perception is not high, so this study assessed stress using only the "negative perception" scale of the sub-factors. The content consists of seven questions, e.g., "How many times did something unexpected happen that made you upset?" and "How many times did you feel that important things were out of control?" The internal compatibility in Park and $\mathrm{Seo}^{38}$ was 0.760 , while in this study it was 0.827 .

\section{Mindfulness Scale}

The mindfulness scale developed by Park $^{42}$ was used, consisting of 20 questions, including "It's hard to focus my mind on one thing or task" and "I often miss what's going on around me." The scale is scored on a five-point Likert scale (totally disagree $=1$, slightly disagree $=2$, neutral $=3$, slightly agree $=4$, and totally agree $=5$ ). This scale comprises four subfactors: concentration, critical acceptance, current awareness, and de-centralization.

The questions are reverse-scored, meaning that the lower the score, the greater the mindfulness. In this study, the collected data were scored such that the higher the score, the greater the mindfulness.

In Park, ${ }^{42}$ the reliability of the mindfulness scale was shown by an internal consistency of 0.88 , with values for concentration of attention of 0.79 , critical acceptance of 0.82 , present self-awareness of 0.76 , and de-centeredness of 0.83 . Its internal consistency in this study was 0.950 .

\section{Five-Factor Personality Scale}

Based on the NEO-PI-R five-factor scale developed by Costa and $\mathrm{MaCrae},{ }^{43}$ Lee and $\mathrm{Ahn}^{44}$ developed the five-factor personality scale used in this study. The scale comprises 25 questions, with sub-factors of extroversion, agreeableness, conscientiousness, neuroticism, and openness to experience, each including 5 questions. The content of conscientiousness examined in this paper was measured with the items, "I think I organize and manage people well," "I strive to achieve the goals
I set," "I try to control myself," and "I certainly handle my duties." The question consists of a five-point Likert scale (totally disagree $=1$, slightly disagree $=2$, neutral $=3$, slightly agree $=4$, and totally agree $=5$ ). In Park, ${ }^{45}$ the internal consistency was 0.77 , and the internal consistency of this scale in this study was 0.779 .

\section{Data analysis}

Data from this study were analyzed with SPSS 18.0 (SPSS Inc., Chicago, IL, USA) and AMOS 21.0 (IBM Corp, Armonk, NY, USA). The specific procedure was as follows: first, a descriptive statistical analysis was conducted to identify the demographic characteristics and reliability of all measures. Second, structural equation modelling was performed using AMOS 21.0 , and the research hypothesis was verified by considering the path coefficients of the structural equation model. The results of correlation analysis were presented in Table 3.

\section{Structural equation model analysis}

A research model was constructed to examine whether stress affects Internet game addiction through conscientiousness among the five factors of mindfulness and personality. Internet game addiction is an independent variable and stress is a single dependent variable, while mindfulness is a parameter measured with attention, critical acceptance, current awareness, and decentralism. Among the five parameters of personality, factors other than integrity were removed from the model due to the lack of significant condensation.

To confirm the suitability of the model, the fit of the research model was verified and compared with that of a competing model. The model's goodness-of-fit assessment was determined by the $\chi^{2}$ value and goodness-of-fit index.

The same model may or may not be rejected depending on its size, so CFI, TLI, and RMSEA were calculated. CFI and TLI represent good suitability for values above 0.09 , RMSEA values below 0.05 , good fit if below 0.08 , and good fit if below 0.10 are normally considered. ${ }^{46}$

This study was approved by the Korea Counseling Graduate University Institutional Review Board (17-2-R-02-01).

\section{RESULTS}

\section{Structural equation model analysis}

Verifiable factor analysis was conducted to determine the validity of the measurements before analysis. Verification confirmed that the fit of the measurement model was good: $\chi^{2}=$ $46.319(\mathrm{df}=16, \mathrm{p}=0.001), \mathrm{CFI}=0.982$, TLI=0.969, RMSEA $=$ $0.069,90 \%$ confidence interval $=(0.046,0.092)$. In addition, the factor load of the measurement variables for the potential variables was significant at $p<0.001$. Therefore, the measurement model in this study was appropriately designed. The re- 
Table 3. Correlation coefficients between variables $(\mathrm{N}=400)$

\begin{tabular}{|c|c|c|c|c|c|c|c|c|c|c|c|c|c|c|}
\hline & 1 & 2 & 3 & 4 & 5 & 6 & 7 & 8 & 9 & 10 & 11 & 12 & 13 & 14 \\
\hline 1 Negative perception 1 & - & & & & & & & & & & & & & \\
\hline 2 Negative perception 2 & $0.617^{*}$ & - & & & & & & & & & & & & \\
\hline 3 Total stress & $0.881^{*}$ & $0.916^{*}$ & - & & & & & & & & & & & \\
\hline 4 Internet game addiction & $0.185^{*}$ & $0.127^{\dagger}$ & $0.171^{*}$ & - & & & & & & & & & & \\
\hline 5 De-centered attention & $-0.414^{*}$ & $-0.314^{*}$ & $-0.400^{*}$ & * $-0.303 *$ & - & & & & & & & & & \\
\hline 6 Present awareness & $-0.327^{*}$ & $-0.216^{*}$ & $-0.296^{*}$ & * $-0.401^{*}$ & $0.678^{*}$ & - & & & & & & & & \\
\hline $\begin{array}{l}7 \text { Non-judgemental } \\
\text { acceptance }\end{array}$ & $-0.313^{*}$ & $-0.223^{*}$ & $-0.293^{*}$ & * $-0.423^{*}$ & $0.728^{*}$ & $0.805^{*}$ & - & & & & & & & \\
\hline 8 Concentration & $-0.308^{*}$ & $-0.214^{*}$ & $-0.285^{*}$ & $-0.462^{*}$ & $0.697^{*}$ & $0.792 *$ & $0.840^{*}$ & - & & & & & & \\
\hline 9 Total mindfulness & $-0.379 *$ & $-0.269^{*}$ & $-0.355^{*}$ & $-0.436^{*}$ & $0.865^{*}$ & $0.906^{*}$ & $0.931^{*}$ & $0.914^{*}$ & - & & & & & \\
\hline 10 Extraversion & $-0.264^{*}$ & $-0.188^{*}$ & $-0.248^{*}$ & $-0.170^{*}$ & $0.309^{*}$ & $0.291^{*}$ & $0.261^{*}$ & $0.299 *$ & $0.321^{*}$ & - & & & & \\
\hline 11 Conscientiousness & $-0.206^{*}$ & $-0.144^{*}$ & $-0.192^{*}$ & $-0.215^{*}$ & $0.233^{*}$ & $0.253^{*}$ & $0.250^{*}$ & $0.325^{*}$ & $0.291^{*}$ & $0.661^{*}$ & - & & & \\
\hline 12 Neuroticism & $0.395^{*}$ & $0.315^{*}$ & $0.391^{*}$ & $0.306^{*}$ & $-0.569 *$ & $-0.483^{*}$ & $-0.490^{*}$ & $-0.506^{*}$ & $-0.568^{*}$ & $-0.269^{*}$ & $-0.173^{*}$ & - & & \\
\hline 13 Agreeableness & $-0.114^{\dagger}$ & -0.050 & -0.088 & -0.081 & 0.058 & 0.047 & 0.051 & 0.075 & 0.063 & $0.506^{*}$ & $0.433^{*}$ & -0.022 & - & \\
\hline 14 Openness & -0.019 & 0.074 & 0.035 & -0.035 & 0.000 & 0.072 & 0.005 & 0.020 & 0.027 & $0.433^{*}$ & $0.398^{*}$ & 0.077 & $0.316^{*}$ & - \\
\hline
\end{tabular}

${ }^{*} \mathrm{p}<0.01 ;{ }^{\dagger} \mathrm{p}<0.05$

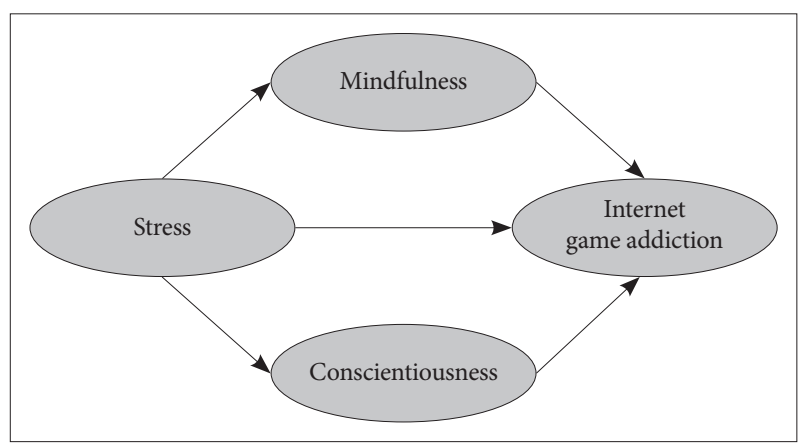

Figure 1. Research mode.

search model and measurement model are presented in Figures 1 and 2 respectively.

\section{Verification of the research model and competing model}

Figure 3 shows the research model used to verify the effectiveness of mindfulness and conscientiousness, a variable that mediates between stress and Internet game addiction, and the competing model is shown in Figure 4. The research model is a partial model, while the competing model is a complete model.

The research model validated the data as appropriate, but the path from stress to Internet game addiction was not statistically significant. Validation of the competition model also found that it was appropriate, as $\Delta \chi^{2}<3.84$ when verifying the differences between the suitability of the competitive model and the study model. These results indicate that the differences in explanatory power between the two models were not statistically significant, so a more succinct, statistically insignificant path was chosen as the final model. These results were presented in Ta-

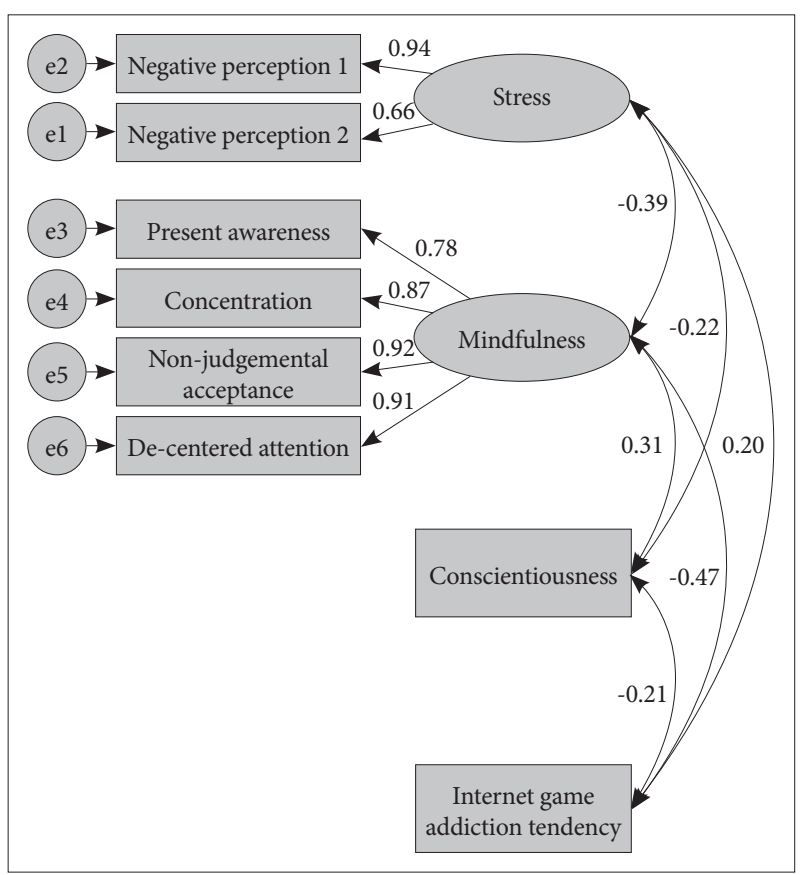

Figure 2. Verifying factors analysis for the measurement model.

ble 4 . The path coefficients for the last selected study model are listed in Table 5.

\section{Verification of the effects of mindfulness and conscientiousness on the effect of stress on internet game addiction tendency}

Bootstrap analysis and Sobel verification were conducted to verify the statistical significance of the mediating path from stress to the internet gaming addiction tendency. According 


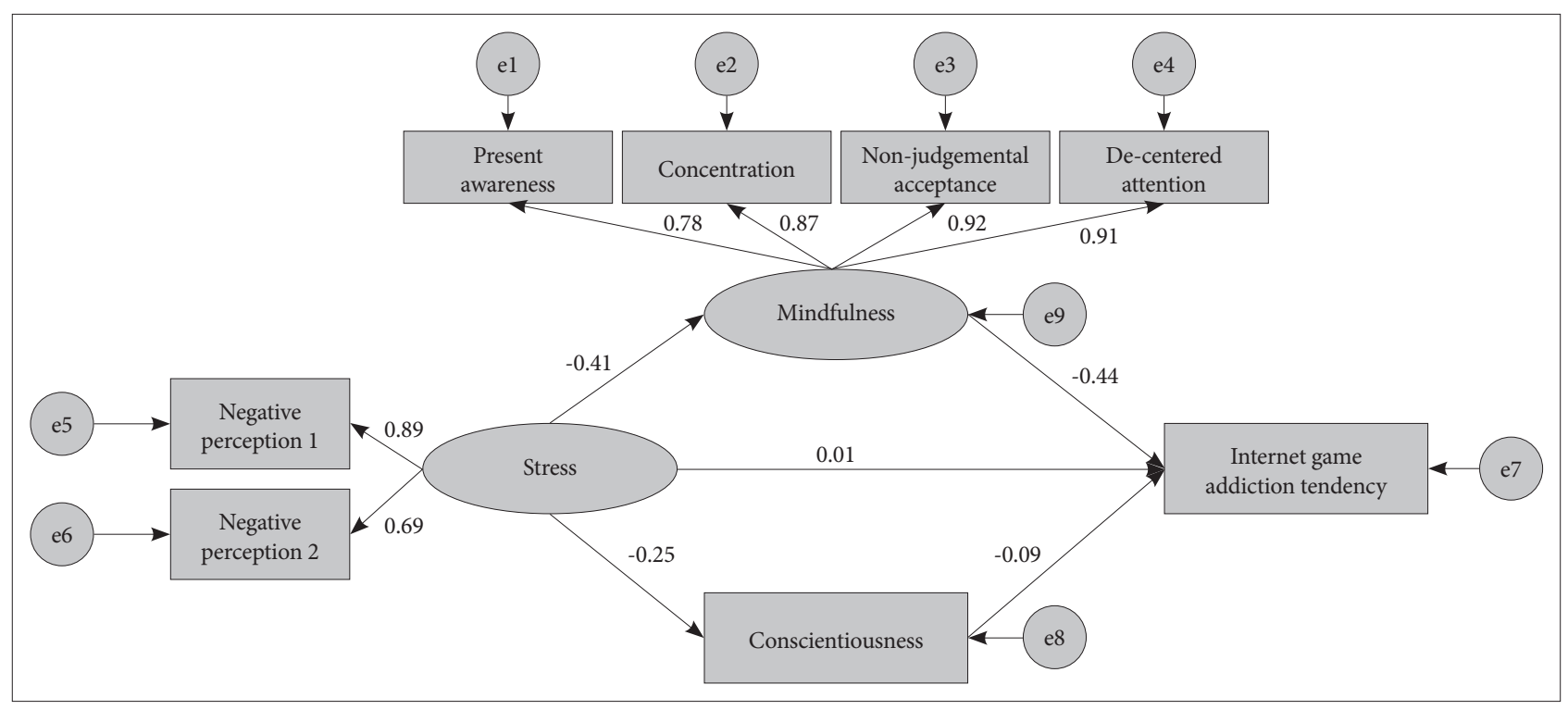

Figure 3. Research model (partial model).

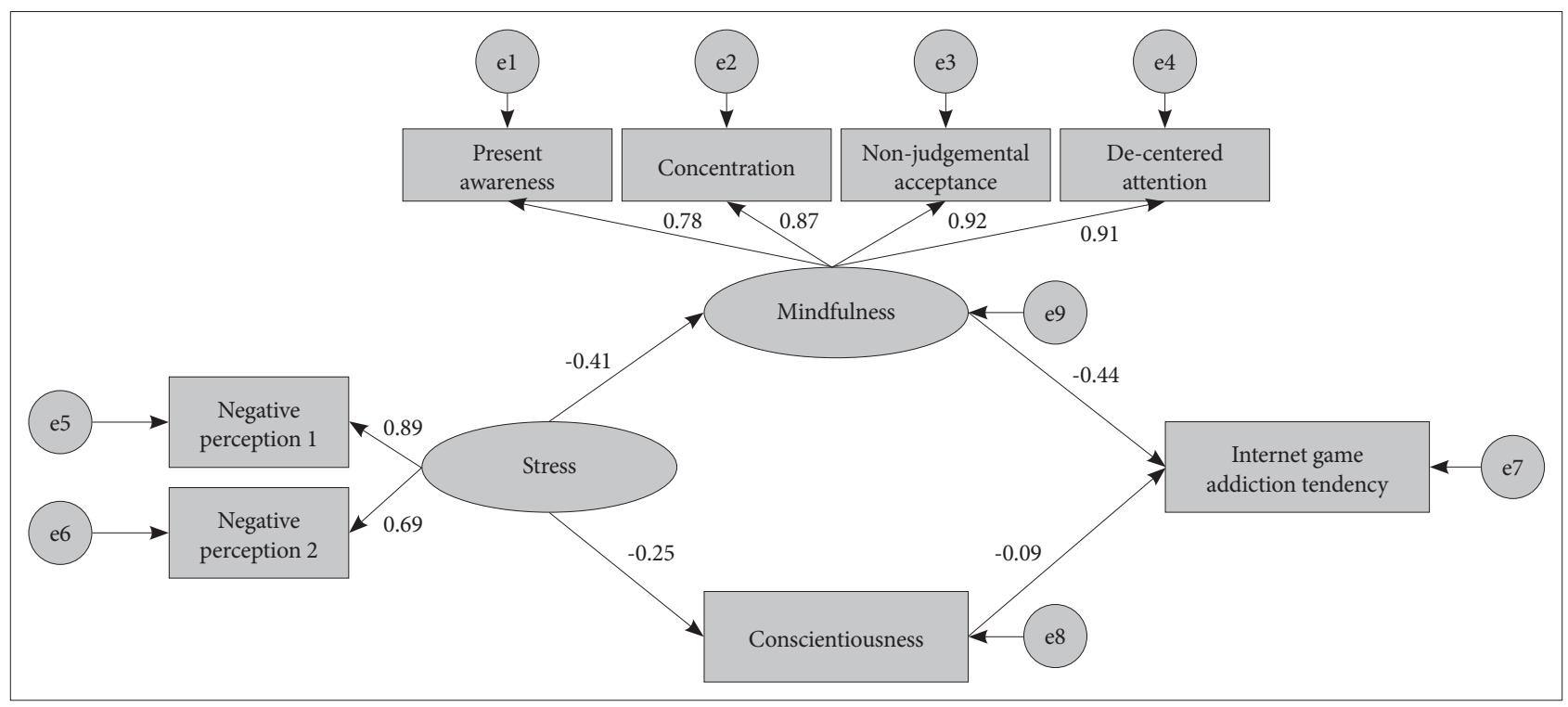

Figure 4. Competitive model (full-mediating model).

Table 4. Comparing study models and competition models to suitability

\begin{tabular}{lccccc}
\hline & $\chi^{2}$ & df & TLI & CFI & RMSEA \\
\hline Research model & 67.724 & 17 & 0.951 & 0.970 & 0.086 \\
Competing model & 67.740 & 18 & 0.971 & 0.971 & 0.083 \\
\hline
\end{tabular}

TLI, Tucker-Lewis Index; CFI, Conparative Fit Index

to the Sobel test results, both pathways were significant. These results are presented in Table 6. The mediating path was also found to be significant in the bootstrap analysis result. It was found that the value in the $95 \%$ confidence interval did not contain 0 , indicating that the mediation pathways were significant. These results are also presented in Table 6.

\section{DISCUSSION}

In this study, we examined whether stress affects the tendency of Internet game addiction and investigated the influence of conscientiousness among the five factors in mind and personality as a variable that can cause Internet game use to decrease even in stressful situations.

The main results of this study are as follows: first, there is a consistent correlation between stress and Internet game addiction tendencies. These results support the results of studies showing that the greater the stress, the greater the likelihood of addiction to Internet games. ${ }^{17,46,47}$ These results are similar to studies examining the correlation between stress and Internet addic- 
Table 5. Path coefficients for the final model

\begin{tabular}{lcccc}
\hline \multicolumn{1}{c}{ Path } & Non-standardization factor & Standardization factor & SE & CR \\
\hline Stress $\rightarrow$ mindfulness & -0.723 & -0.414 & 0.119 & -6.069 \\
Stress $\rightarrow$ conscientiousness & -0.315 & -0.246 & 0.075 & -4.221 \\
Mindfulness $\rightarrow$ Internet game addiction & -0.252 & -0.444 & 0.028 & -8.925 \\
Conscientiousness $\rightarrow$ Internet game addiction & -0.068 & -0.088 & 0.035 & -1.958 \\
\hline
\end{tabular}

SE, standard error; CR, critical ratio

Table 6. Sobel verification results

\begin{tabular}{lccc}
\hline \multicolumn{1}{c}{ Path } & Non-standardized estimation & Standard error & Sobel verification \\
\hline Stress $\rightarrow$ mindfulness & -1.222 & -0.057 & 5.929 \\
Mindfulness $\rightarrow$ Internet game addiction & 0.161 & 0.006 & 2.697 \\
Stress $\rightarrow$ conscientiousness & -0.112 & -0.147 & 0.039 \\
Conscientiousness $\rightarrow$ Internet game addiction & 0.029 & $(0.137-0.282)$ & \\
Bootstrap results of the mediating path 95\% CI & & \\
\hline
\end{tabular}

tion. ${ }^{48-53}$ Both Internet game addiction and Internet addiction are correlated with stress, which can be inferred from earlier studies showing that game addiction and Internet addiction are related. ${ }^{54,55}$

Second, extroversion, conscientiousness, and neuroticism among the five factors of personality and mindfulness showed a significant correlation with stress and Internet game addiction tendency. The relationship between stress and mindfulness shows the same results as were found in several studies conducted since Kabat-Zinn introduced mindfulness as a way to reduce stress. ${ }^{18,20,21,56}$ Of the relationships between the subcomponents of stress and care, the highest correlation was shown with decentralism. These results support prior studies suggesting that the greater the decentralism, the lower the stress. ${ }^{57,58}$ Other sub-variates of mindfulness also showed a relationship between stress and ineligibility, as found in other studies. .9,60 $^{2}$ An attitude that allows the objective observation of the state of the mind through mindfulness will not show a pattern of seeking to prove negative thoughts related to stress events or constantly argue about them. Proper care of the mind facilitates less stressful experiences through a distancing from thinking and emotions. ${ }^{61}$

Next, the relationship between mindfulness and the tendency to become addicted to Internet games supports the results of an earlier study, ${ }^{62}$ as well as a teacher's study dealing with mind-caring and direct route to Internet game addiction in Korea, ${ }^{63}$ and a further study showing that Internet addiction decreases as mind-caring increases. These above-mentioned results concerning game addiction and Internet addiction ${ }^{54,55}$ found that the higher the mindfulness, the lower the tendency of Internet game addiction. If addiction behavior is the result of an automatic response of the mind, the individual's appropriate mind-set can control it by making it possible to recognize and control addiction, a habitual phenomenon that is automatically handled throughmindfulness. ${ }^{64}$

Neuropathy showed static correlation with both stress and Internet game addiction, while extroversion and conscientiousness showed an insignificant correlation between stress and Internet game addiction. These results are similar to those of studies that identified relationships between neurosis and stress. ${ }^{28,65-67}$ A person with a high neurological tendency is more likely to be exposed to stress and is more likely to be under stress than others. ${ }^{68}$ Extroverts were also found to be flexible in studies that identified their relationship with extroversion and stress. ${ }^{69,70}$ Extroverts are less stressed by responding to rational actions and positive thinking, which are methods for actively coping with problems. ${ }^{71}$ The results of studies with integrity and stress also support this conclusion. ${ }^{28,65,69,70,72,73}$ A person with a high level of integrity tries to address stress situations and appears to address the emotional pain and anxiety caused by stress. ${ }^{74}$

In terms of the five factors and the tendency to Internet game addiction, neurosis was not related to the tendency to Internet game addiction and is not related to extroversion and conscientiousness. This is similar to Lee's ${ }^{35}$ result that in the relationship between the five factors and Internet game addiction, neurological disorders are statistically related to integrity, openness, affinity, and extroversion, as well as to the results of previous studies that looked at the correlation between the five factors and Internet addiction. . $^{34,75,76}$

This study found that among personality factors, neuroticism, extroversion, and conscientiousness are related to the tendency of Internet game addiction. The more neurosis or less extroversion and conscientiousness an individual has, the greater the likelihood of becoming addicted to Internet games. People with high levels of neuroticism may show a tendency to fall into Internet game addiction because of low emotional stabil- 
ity, a tendency to fail to adapt in everyday life, while those with high conscientiousness may show less tendency to Internet game addiction because they are goal-oriented and achievement-oriented, thus striving to control their behavior. Individuals high in extroversion like to meet and date others, showing that they expect to maintain more intimate relationships. Thus, they appear to have lower Internet game addiction tendencies due to their orientation toward the real world rather than virtual subjects.

Third, the structural equation model was verified to check whether mindfulness and conscientiousness act as parameters in the relationship between stress and Internet game addiction tendencies. Verification found the parameters to fully mediate the effects of stress on Internet game addiction tendency. In the association of stress and Internet game addiction tendency, mindfulness and conscientiousness showed a major relationship with stress and Internet game addiction.

Mindfulness had a mediating effect on stress and Internet game addiction such that the higher the stress, the lower the mindfulness, and the lower the mindset, the higher the tendency to Internet game addiction. There has been no study of mind-caring and Internet game addiction among Korean studies, but this result is similar to that of a study ${ }^{53}$ that found mindcaring to mediate stress and Internet addiction, and another study. ${ }^{59}$ Addiction controls the individual if it arises as an automatic response of the mind. Mindfulness allows the individual to make decisions about control by noticing and considering habitual behaviors that are automatically handled.

Among the five factors, the mediating effect of conscientiousness and tendency to increased Internet game addiction is such that the higher the stress, the lower the level of conscientiousness and the higher the tendency to increased Internet game addiction. These results are similar to those of one study ${ }^{70}$ that found that high conscientiousness reduces job stress, and another that high conscientiousness reduces Internet game addiction. ${ }^{35}$

This study has the following significance in helping physicians treat the overuse of games. First, this study examined the variables that influence adult Internet game addiction tendencies. Most earlier studies of game addiction involved children and teenagers. There is a need to intervene for present-day adults who were teenagers when Internet games first became popular, and to do so it is necessary to understand the tendency of adults to become addicted to Internet games.

Second, this study confirmed mindfulness and conscientiousness as variables that mediate the relationship between stress and Internet game addiction tendency. There has been no previous study examining the mediating effects of both mental care and conscientiousness between stress and the tendency of Internet game addiction. This study thus allows us to further expand our knowledge of the path from stress to Internet game addiction.

Third, mindfulness can be used to reduce Internet game addiction through counseling processes or programs. It is believed that existing mindfulness programs can be applied as interventions in Internet game addiction based on the results of expanded research. ${ }^{59,77}$

During counseling, the counselor will assign tasks to accurately understand the stress and feelings of interviewees addicted to games so as to objectively view their experiences in situations even outside the consultation period, and then give feedback regarding self-control by helping them recognize stress, sexual emotions, and behavior. This repetition of the process will allow the interviewee to positively use games that were previously used only as a means of avoidance.

We will also be able to train individuals showing a tendency to Internet game addiction to realize and control what happens automatically. By controlling themselves through mindfulness, individuals might be trained to use games well and reduce excessive game use.

Fourth, the higher the level of conscientiousness among the five factors, the stronger their stress and the lower their tendency to Internet game addiction. This finding may serve as a basis for establishing a counseling intervention strategy that can help physicians express the factors of conscientiousness found in the counseling session.

In adulthood, one's personality can continue to change due to the circumstances in which responsibilities are given. ${ }^{29}$ During counseling, counselors will be able to improve their integrity by helping interviewees change their environment to the greatest extent possible by developing relationships with counselors and those around them. As the level of conscientiousness increases, we can expect that the tendency of the inpatients to become game addicts to concurrently decrease.

Finally, we point out the following limitations and suggestions for subsequent research. First, the study was limited to those between their 20s and 40s. However, 58.6\% of game users in their 50 s or older and $51.9 \%$ of those aged 60 to 65 years are expected to need study in addition to those in their 20 s and 30 s. In addition, the proportion of subjects in their early twenties was only $9 \%$ in the subjects of this study, so the moderating effect according to the age group could not be verified. However, in the follow-up study, it may be necessary to conduct a comparative study between the group from the late teens to the early 20 s and the adult group thereafter. This is because mediating effects may differ depending on age.

Second, the measure of Internet game addiction used in this study consists of questions prepared based on the criteria of Internet gaming disorder in the Conditions for Further Study (DSM-5). Therefore, as debate over the conceptualization and appropriateness of diagnosis standards for Internet game ad- 
diction still persists, the study of appropriate measures should continue.

\section{Availability of Data and Material}

The datasets generated or analyzed during the study are available from the corresponding author on reasonable request.

\section{Conflicts of Interest}

The authors have no potential conflicts of interest to disclose.

\section{Author Contributions}

Conceptualization: all authors. Formal analysis: Jae Woo Park, Taeyeong Choi. Data curation: Jae Woo Park, Taeyeoung Choi. Investigation: all authors. Project administration: Taeyeoung Choi. Investigation: all authors. Methodology: Jae Woo Park, Taeyeong Choi. Resources: all authors. Supervision: Jae Woo Park, Dai-jin Kim. Validation: Jae Woo Park, Dai-jin Kim. Visualization: Taeyeong Choi. Writing_original draft: Taeyeong Choi. Writing—review \& editing: all authors.

\section{ORCID iDs}

Taeyeong Choi

Jae Woo Park

https://orcid.org/0000-0002-8337-1960

Dai-jin Kim

https://orcid.org/0000-0001-9408-5639

\section{Funding Statement}

None.

\section{REFERENCES}

1. Griffiths MD. Amusement machine playing in childhood and adolescence: a comparative analysis of video games and fruit machines. J Adolesc 1991;14:53-73.

2. Young KS, Yue XD, Ying L. Prevalence Estimates and Etiologic Models of Internet Addiction. In: Young KS, de Abreu CN, Editors. Internet Addictions: A Handbook and Guide to Evaluation and Treatment. Hoboken, NJ: John Wiley \& Sons; 2011, p.3-17.

3. Choi HS, Yong JS, Kim KH. Development and feasibility of game addiction scale for Korean adults. Korean J Health Psychol 2013;18:709726.

4. Jang SM, Kyung SY. The relationship between college students' job stress and addiction behavior. Health Soc Stud 2013;33:518-546.

5. Jang KW, Lee JH. Development of a Korean version of Internet game addiction/admission scale (adults) and validation of validity. Korean J Health Psychol 2007;12:517-527.

6. Lee HC, Choi YK, Lee SM, Ban JC, Lee SY. Developing a self-reporting scale for behavioral symptoms of adult Internet pathological use. Korean J Clin Psychol 2007;26:765-791.

7. Selye H. The Stress of Life. New York: McGraw-Hill; 1976.

8. Lazarus RS. From psychological stress to the emotions: a history of changing outlooks. Annu Rev Psychol 1993;44:1-22.

9. Lazarus RS, Folkman S. Stress, Appraisal, and Coping. New York: Springer. (Played by Kim JH), Seoul: Daegwang Cultural History; 1984.

10. Hudek KJ, Cardum I, Kalbić MB. The sources of stress and coping styles as mediators and moderators of the relationship between personality traits and physical symptoms. Rev Psychol 2006;12:91-101.

11. Endler NS, Parker JD. Multidimensional assessment of copying: a critical evaluation. J Pers Soc Psychol 1990;58:844-854.

12. Kim JW, Lee JJ. A comparative culture study on leisure and quality of life. Korean J Soc Pers Psychol 2005;19:1-15.

13. Kimball A, Freysinger VJ. Leisure, stress, and coping: the sport participation of collegiate study-athletes. Leis Stud 2003;25:115-141.

14. Young KS. What makes the Internet addictive: Potential explanations for pathological Internet use. Chicago: In 105th annual conference of

the American Psychological Association, 1997, Vol. 15, p.12-30

15. National Information Society Agency. Available at: https://www.nia. or.kr/site/nia_kor/main.do. Accessed June 20, 2018.

16. Korea Creative Content Agency. Available at: http://www.kocca.kr/cop/ main.do. Accessed June 20, 2018.

17. Kang MS, Kim YS, Kim YH. The effect of the daily stress of university students on game addiction: The effect of adjusting interpersonal technology. J Serv Res Stud 2016;6:65-82.

18. Kabat-Zinn J. Full Catastrophe Living: Using the Wisdom of Your Body and Mind to Face Stress, Pain, and Illness. New York: Delta Press; 1990.

19. Kim KH. Mindfulness, self-control and wisdom. Korean J Health Psychol 2008;13:285-306.

20. Teasdale JD, Segal ZV, Williams JMG, Ridgway VA, Soulsby JM, Lau MA. Prevention of relapse/recurrence in major depression by mindfulness-based cognitive therapy. J Consult Clin Psychol 2000;68:615623.

21. Jang HG. Application of meditation to the treatment of stress-related diseases. J Psychol Health 2004;9:471-492.

22. Astin JA. Stress restructuring through mindfulness meditation: Effects on psychological symptomatology, sense of control, and spiritual experiences. Psychother Psychosom 1997;66:97-106.

23. Brown KW, Ryan RM. The benefits of being present: mindfulness and its role in psychological well-being. J Pers Soc Psychol 2003;84:822-848.

24. Groves P, Farmer R. Buddhism and addictions. Addiction Res 1994;2: 183-194.

25. Kim SJ. Development and Effectiveness of Mind-Set-Based InternetHungry Self-Regulating Programs. Daejeon: Chungnam National doctoral dissertation; 2011.

26. Im SH, Kwon SJ, Kim, KH. The effect of autonomy and care-taking on teenagers' motivation to control games and the use of problematic games. Korean J Psychol Gen 2013;32:903-930.

27. Bolger N, Zuckerman A. A framework for studying personality in the stress process. J Pers Soc Psychol 1995;69:890-902.

28. Vollath M, Torgersen S. Personality types and coping. Pers Individ Diff 2000;29:367-378.

29. Srivastava S, John OP, Gosling SD, Potter J. Development of personality in early and middle adulthood: set like plaster or persistent change? J Pers Soc Sci 2003;84:1041-1053.

30. Neyer FJ, Asendorpf JB. Personality-relationship transaction in young adulthood. J Pers Soc Psychol 2001;81:1190-1204.

31. Roberts BW. Plaster or plasticity: are adult work experiences associated with personality change in women? J Pers 1997;65:205-232.

32. Roberts BW, Jackson JJ, Fayard JV, Edmonds G, Meints J. Conscientiousness. In: Leary MR, Hoyle RH, Editors. Handbook of Individual Differences in Social Behavior. New York: The Guilford Press; 2009, p.369-381.

33. Costa PT, McCrae RR. Normal personality assessment in clinical practice: the NEO Personality Inventory. Psychol Assess 1992;4:5-13.

34. Kuss DJ, Van Rooij AJ, Shorter GW, Griffiths MD, van de Mheen D. Internet addiction in adolescents: prevalence and risk factors. Comput Human Behav 2013;29:1987-1996.

35. Lee YK. Achievement Goal Orientation and Internet Game Addiction Relationship: The Parameter Effect of Personality Characteristics. Jeonju: Jeonbuk National University Doctoral Dissertation; 2013.

36. Petry NM, Rehbein F, Gentile DA, Lemens JS, Rumpf HJ, Mößle T, et al. An international consensus for assessing Internet gaming disorder using the new DSM-5 approach. Addiction 2014;109:1399-1406.

37. Cohen S, Kamarck T, Mermelstein R. A global measure of force stress J Health Soc Behav 1983;24:385-396.

38. Park JH, Seo YS. A study on the rationalization of perceived stress in Korean version of college students. Korean J Psychol Gen 2010;29:611629.

39. Mimura C, Griffiths P. A Japanese version of the Perceived Stress Scale: cross-cultural translation and equivalence. BMC Psychiatry 2008;8:85.

40. Leung DY, Lam TH, Chan SS. Three versions of Perceived Stress Scale: validation in a sample of Chinese cardiac patients who smoke. BMC 
Public Health 2010;10:513.

41. Taylor JM. Psychometric analysis of the Ten-Item Perceived Stress Scale. Psychol Assess 2015;27:90-101.

42. Park SH. Development of a Mental Scale. Seoul: Catholic University doctoral dissertation; 2006.

43. Costa PT, McCrae RR. Revised NEO Personality Inventory (NEO PI$\mathrm{R})$ and NEO Five-Factor Inventory (NEO-FFI): Professional Manual. Odesa, FL: Psychological Assessment Resources, Incorporated; 1992.

44. Lee KI, Ahn CG. Clinical use of NEO-PI-R. Korean J Counsel Psychother 1996;8:65-79.

45. Park MH. Relationship of Big Five Personality Factors, Self-Esteem and SNS Addiction Tendency in College Students. Seoul: Kyungsung University Doctoral Dissertation; 2014.

46. Kwon SJ, Y Zhen, HW Cho. The effect of stress on adolescent gaming addiction: the comparison of Korean and Chinese high school students. Korean Psychol Conf Arch 2013;259-259.

47. Oh IS, Woo KG. Exploring psychological and social factors related to computer game addiction among elementary school students. Cons Stud 2005;6:563-571.

48. Hong SH. A Study on the Effect of Youth Stress on Internet Addiction. Seoul: Ewha Womans University Doctoral Dissertation; 2006.

49. Jang JH, Yoo J, Kim HS, Choi HN. Psychological and environmental factors that influence middle school students' experience of Internet addiction and Internet compensation. Cons Stud 2003;4:237-252.

50. Jo JS. A Study on the Difference in the Method of Coping with the stress and the Perceptible Level of stress by Addicted Degree to the Internet among Middle School Students. Jeonju: Jeonju University Doctoral Dissertation; 2004.

51. Seo SY, Lee YH. Routine stress, social support, the relationship between intolerance and Internet addiction. Korean J Clin Psychol 2007;26:391405.

52. Sung DH. A Study on the Relationship Between Juvenile's Internet Addiction and Stress. Iksan: Wonkwang University Doctoral Dissertation; 2005.

53. Song WJ. The Effect of Stress on Internet Addiction: The Effect of SelfControl and Consciousness on the Mediation. Seoul: Master's Thesis Korea Counseling Graduate University Master's Thesis; 2016.

54. Jang JH. The effect of internet desire and psychological social variants on game addiction in Jeong So-nyon: Comparison by Gender. J Future Orient Youth Soc 2005;2:39-55.

55. Jang MK, Lee EK. The effect of the desire to use the Internet and the parents-related spokesperson on game addiction in elementary school students. Korean J Counsel Psychother 2007;19:1125-1138.

56. Park K. The mediating effect of high-profile and mindfulness in relation to perceived stress and depression. Korean J Health Psychol 2010; 15:617-634.

57. Jung ES, Son JR. The effectiveness of MBCT programs on Internet addiction levels, anxiety and stress among college students. Korean J Clin Psychol 2011;30:825-843.

58. Kim YS. The relationship between emotional intelligence and stress of art psychological consultants: the mediating effect of decorativization. Art Psychother Res 2016;12:43-60.

59. Jeon HS, Son JR. The role of a medium of mindfulness and anger-repeating in the relationship between stress and dysfunctional anger.
Korean J Clin Psychol 2012;31:907-922.

60. Park NS. Structural analysis of the relationship between office workers' care, stress, self-respect, creativity, exhaustion, and organizational immersion. Health Soc Sci 2012;32:93-114.

61. Segal VZ, Williams GJM, Teasdale DJ. Mindfulness-Based Cognitive Therapy for Depression: A New Treatment for Preventing Relapse of Depression (1st Ed.). New York: The Guilford Press; 2002.

62. Im SH. The Effect of Autonomy and Caring Mind on Teenagers' Motivation to Control the Game. Daejeon: Chungnam National University Doctoral Dissertation; 2013.

63. Choi HJ. The Effects of Job Stress on Smartphone Game Addiction: The Mediation Effect of Interpersonal Concern and the Adjustment Effect of Mind-Careering. Gwangju: Chosun University Doctoral Dissertation; 2018.

64. Oh EJ, Jang SH. The relationship between adolescents' social support and self-identity and cell phone addiction. Youth Welf Res 2009;11:2544.

65. Baek YM. The center is on the mediated effects of self-efficiency on the relationship between college students' personality factors and their stress coping methods-neuropathy and conscientiousness. J Korean Soc Sci Technol 2017;18:219-227.

66. Han TY. The school scene stress of adolescents. Korean J Sch Psychol 2005;2:177-197.

67. Kim NS, Park SM. Relationship between personality characteristics and stress response behavior. Second Educ Res 2010;22:21-46.

68. Langford C, Glendon AI. Effects of neuroticism, extraversion, circadian type and age on reported driver stress. Work Stress 2002;16:316-334.

69. Jung SW. Personality 5 of secondary school teachers and the relationship between stress response and psychological well-being. J Psychol Behav 2012;4:1-24.

70. Kim JH, Hwang OK. The media effect of emotional intelligence between extroversion, conscientiousness and job stress of social welfare facility workers. Korean J Soc Welf Res 2011;29:57-79.

71. Lee OJ. Stress management style based on the personality characteristics of high school students. Korean J Psychol Health 2002;7:487-501.

72. Besser A, Shackelford TK. Mediation of the effects of the effects of the big five personality Dimensions on essential food and related effects by force-funded situational stress: a quasi-field study of vacationers. Pers Individ Diff 2007;42:1333-1346.

73. Ebstrup JF, Eplov LF, Pisinger C, Jørgensen T. Association between the Five Factor personality traits and perceived stress: is the effect mediated by general self-efficiency? Anxiety Stress Coping 2011;24:407-419.

74. Kang EB. The Effect of Controlling Stress on the Relationship between Personality Factors and Academic Delay: Diligence and Neuropathy. Seoul: Seoul University Doctoral Dissertation; 2013.

75. Lee GH. The Effect of the Personality Traits of Elementary School Students and the Functional Characteristics of Their Families on Internet Addiction. Seoul: Konkuk University Master's Thesis; 2010.

76. Yoon HY. The Relationship between the Personality Characteristics of Elementary School Students and Internet Addiction and School Life Adaptation Based on the NEO Child Personality Test. Seoul: Ewha Womans University Doctoral Dissertation; 2008.

77. Kim SJ, Kim KH. A cognitive approach to improving Internet addiction. Korean J Health Psychol 2013;18:421-446. 